\title{
Solamargine inhibits the migration and invasion of HepG2 cells by blocking epithelial-to-mesenchymal transition
}

\author{
XIAODONG XIE $^{1 *}$, HAITAO ZHU ${ }^{2 *}$, JIA ZHANG $^{1}$, MEIQIN WANG $^{1}$, LI ZHU $^{2}$, \\ ZHEN GUO $^{1}$, WENRONG SHEN ${ }^{1}$ and DONGQING WANG ${ }^{2}$ \\ ${ }^{1}$ Department of Radiology, Jiangsu Cancer Hospital, Jiangsu Institute of Cancer Research, \\ Nanjing Medical University Affiliated Cancer Hospital, Nanjing, Jiangsu 210000; ${ }^{2}$ Department of Radiology, \\ The Affiliated Hospital of Jiangsu University, Zhenjiang, Jiangsu 212013, P.R. China
}

Received October 22, 2015; Accepted March 30, 2017

DOI: $10.3892 / \mathrm{ol} .2017 .6147$

\begin{abstract}
Solamargine (SM), a steroidal alkaloid glycoside purified from the Chinese traditional herb Solanum incanum, is known to possess various biological activities. However, only a few previous studies have reported the anti-metastatic activity of SM. In the present study, the inhibitory effects of SM on metastatic action were investigated in human HepG2 cells. The proliferation effects of SM on the HepG2 cells was evaluated by MTT and colony formation assays. Wound-healing and Transwell assays were performed to examine the migration and invasion effects on SM-treated HepG2 cells. The epithelial-to-mesenchymal transition (EMT)-associated markers (E-cadherin, Vimentin and N-cadherin) were detected by western blotting analysis. In the present study, MTT and colony formation assays indicated that SM suppressed HepG2 cell viability in a dose-dependent manner. The wound-healing and Transwell assays revealed that the migration and invasion activities were significantly inhibited following exposure to SM. EMT has been demonstrated to be essential for promoting migration and invasion in tumor cells and has often been characterized with a loss of epithelial markers (E-cadherin) and an increase of mesenchymal markers (Vimentin and $\mathrm{N}$-cadherin). In the western blotting analysis, the expression level of E-cadherin was significantly upregulated compared
\end{abstract}

Correspondence to: Professor Wenrong Shen, Department of Radiology, Jiangsu Cancer Hospital, Jiangsu Institute of Cancer Research, Nanjing Medical University Affiliated Cancer Hospital, 42 Baiziting Road, Nanjing, Jiangsu 210000, P.R. China

E-mail: jszlyyct@sohu.com

Professor Dongqing Wang, Department of Radiology, The Affiliated Hospital of Jiangsu University, 438 Jiefang Road, Zhenjiang, Jiangsu 212013, P.R. China

E-mail: xiaodong8196@126.com

${ }^{*}$ Contributed equally

Key words: solamargine, hepatoblastoma, migration, invasion, epithelial-to-mesenchymal transition with that in the control group, whereas the expression levels of $\mathrm{N}$-cadherin and Vimentin were downregulated. Thus, it was suggested that the underlying mechanism of SM inhibits migration and invasion in HepG2 cells and is associated with suppression of EMT.

\section{Introduction}

Hepatoblastoma is the most common type of pediatric malignant liver tumor in childhood worldwide, and demonstrates an increasing incidence; the incidence is estimated to be $1.2-1.5 /$ million children per year, accounting for $80 \%$ of malignant liver tumors in childhood (1-4). The type of tumor is usually diagnosed prior to the age of 4 years, with poor prognosis and aggressive behavior (5). Despite certain previous studies investigating the metastasis mechanisms underlying the HepG2 cell line (6-8), the mechanisms remain obscure. The approaches to suppress the migration and invasion viability in hepatoblastoma cells remain limited.

Previous studies have suggested that EMT is a crucial process inducing cell cancer migration and invasion $(9,10)$. A growing number of tumors were demonstrated to be involved in the EMT process when migrated and invaded, including pancreatic cancer, colorectal cancer, prostate cancer and breast cancer (11-14).

At the molecular level, a feature of EMT is the loss or decreased expression level of epithelial cell markers, E-cadherin (E-ca), and the upregulation of mesenchymal properties, Vimentin and N-cadherin (N-ca) $(15,16)$. The loss of E-ca is considered to be the primary event of EMT, the consequent loss of E-ca induces enhanced migration and invasion potential of tumor cells (17). Furthermore, the expression level of E-ca is often inversely associated with tumor stage and grade $(18,19)$.

Solamargine (SM) extracted from the Chinese herb Solanum incanum L., is a major steroidal glycoalkaloid and belongs to the Solanaceae (or nightshade) family (20). Our previous study demonstrated that SM strongly inhibited growth and induced apoptosis of HCC cells, and we further investigated mechanisms underlying apoptosis induced by SM (21). Given this effect on the proliferation and apoptosis of HCC cells, the present study aimed to observe and determine 
whether SM contributes to an effective action on metastasis in hepatoblastoma cells and explore the possible underlying mechanisms.

\section{Materials and methods}

Materials. SM (purity >98\%) was purchased from Yilin Biotechnology Co., Ltd. (Shanghai, China). Fetal bovine serum (FBS) and Dulbecco's modified Eagle's medium (DMEM) were obtained from Gibco (Thermo Fisher Scientific, Inc., Waltham, MA, USA). MTT and crystal violet staining solution were purchased from Beyotime Institute of Biotechnology (Shanghai, China). The Transwell was obtained from Corning Incorporated (Corning, NY, USA). Rabbit anti-human monoclonal epithelial-cadherin (E-ca; 1:1,000 dilution; cat. no. 3195S), rabbit anti-human monoclonal $\alpha-\mathrm{N}$-catenin (N-ca; 1:1,000 dilution; cat. no. 2163S), rabbit anti-human monoclonal Vimentin (1:1,000 dilution; cat. no. 5741P) and mouse anti-human monoclonal $\beta$-actin (loading control; 1:1,000 dilution; cat. no. 3700S) primary antibodies were purchased from Cell Signaling Technology, Inc. (Danvers, MA, USA). Horseradish peroxidase-conjugated goat anti-mouse (1:2,000 dilution; cat. no. 7072S) and goat anti-rabbit (1:2,000 dilution; cat. no. 7071S) immunoglobulin G secondary antibodies were purchased from Cell Signaling Technology, Inc. Other chemicals used in the present study were commercial products of reagent grade.

Cell lines and culture. Human hepatoblastoma HepG2 cells were purchased from the Cell Bank of the Chinese Academy of Sciences (Shanghai, China). The HepG2 cells were maintained in DMEM, supplemented with 10\% FBS and $100 \mathrm{U} / \mathrm{ml}$ penicillin (Gibco; Thermo Fisher Scientific, Inc.), as well as $100 \mu \mathrm{g} / \mathrm{ml}$ streptomycin (Gibco; Thermo Fisher Scientific, Inc.) in a humidified atmosphere of $5 \% \mathrm{CO}_{2}$ at $37^{\circ} \mathrm{C}$.

Evaluation of cell viability. Cell viability was detected by MTT assay. HepG2 cells were seeded in 96-well plates (Corning Incorporated) at a density of $2 \times 10^{5}$ and treated with serial concentrations of $0,5,10$ or $20 \mu \mathrm{M} \mathrm{SM}$ for $24 \mathrm{~h}$ at $37^{\circ} \mathrm{C}$. Following incubation, the medium solution was removed and $20 \mu \mathrm{l}$ of medium supplemented with MTT reagent $(5.0 \mathrm{mg} / \mathrm{ml})$ was added to the well. Following a 4-h incubation at $37^{\circ} \mathrm{C}$, the medium solution was removed again. Subsequently, $100 \mu \mathrm{l}$ DMSO was added to each well and agitated for $15 \mathrm{~min}$ at $37^{\circ} \mathrm{C}$. The absorbance at $490 \mathrm{~nm}(\mathrm{~A} 490)$ was determined using an ELISA reader (Bio-Rad 680; Bio-Rad Laboratories, Inc., Hercules, CA, USA). The cell survival ratio was evaluated based on the treated group A490 results vs. the untreated group results.

Colony formation assay. For the colony formation assays, the HepG2 cells were seeded into 6-well plates (Corning Incorporated) at a low density of 500 cells per well. Subsequently, the cells were treated with $0,5,10$ or $20 \mu \mathrm{M}$ SM and incubated for 2 weeks in a humidified atmosphere of $5 \% \mathrm{CO}_{2}$ at $37^{\circ} \mathrm{C}$. Subsequently, the cells were fixed with $4 \%$ paraformaldehyde for $30 \mathrm{~min}$ at room temperature and stained with crystal violet for $15 \mathrm{~min}$ at room temperature, followed with colony counting by eye. Images were captured using a fluorescence microscope (Eclipse TS100; magnification, x10; Nikon Corporation, Tokyo, Japan).

Determination of migration using wound-healing assays. In the wound-healing migration assays, cells were seeded in 6-well plates at a density of $1 \times 10^{6}$ cells/well, incubated for $24 \mathrm{~h}$ at $37^{\circ} \mathrm{C}$ and scratched using a yellow pipette tip when the cells covered the well. The cells were washed with PBS twice to clear the floating cells and various concentrations $(0,5,10$ or $20 \mu \mathrm{M}$ ) of SM were added. Images were captured at 12 and $24 \mathrm{~h}$ using a fluorescence microscope at $\times 40$ magnification.

Evaluation of migration by Transwell assay. Cell migration was determined using the Transwell Boyden chamber containing $8-\mu \mathrm{m}$ pore size membranes (Corning Incorporated). Briefly, suspended HepG2 cells were separately treated with $0,5,10$ or $20 \mu \mathrm{M} \mathrm{SM}$ in serum-free DMEM at a density of $2 \times 10^{5}$ cells, and then added to the upper chamber of the Transwell. DMEM supplemented with $10 \%$ FBS was added to the lower chamber as a chemoattractant. Following incubation for $24 \mathrm{~h}$ at $37^{\circ} \mathrm{C}$, non-invading cells remaining on the upper surface were removed using a wet cotton swab, whereas cells on the lower surface were fixed with $4 \%$ paraformaldehyde for $30 \mathrm{~min}$ at room temperature and stained with crystal violet for $15 \mathrm{~min}$ at room temperature. Images were captured using a fluorescence microscope at x200 magnification.

Matrigel-coated Transwell assay to detect invasion. In the cell invasion experiment, the Transwells were coated with Matrigel (BD Biosciences, Franklin Lakes, NJ, USA). Subsequent steps were similar to those described in the migration assay protocol, and detailed procedures were performed as previously described (22).

Western blot analysis. Western blot analysis was performed as described previously (21), with minor modifications. Cells were treated with $0,5,10$ or $20 \mu \mathrm{M}$ SM for $24 \mathrm{~h}$. Cell lysates were collected using a lysis buffer (Beyotime Institute of Biotechnology) and $\beta$-actin was used as the loading control. The cell lysate proteins were separated by electrophoresis based on their molecular weight, size and charge, and $40 \mu \mathrm{g} / \mathrm{lane}$ cell lysate proteins were loaded and separated using 10\% SDS-PAGE by electrophoresis for $2 \mathrm{~h}$ at room temperature. They were then transferred onto polyvinylidene difluoride membranes (EMD Millipore, Billerica, MA, USA) for $90 \mathrm{~min}$ at $-20^{\circ} \mathrm{C}$, then incubated with $3 \%$ bovine serum albumin for $1 \mathrm{~h}$ at room temperature. Subsequently, the primary antibodies as aforementioned were added and incubated overnight at $4^{\circ} \mathrm{C}$. Following this, cells were incubated with secondary antibodies as aforementioned for $1 \mathrm{~h}$ at room temperature. Immunoreactive bands were detected using chemiluminescence reagent (EMD Millipore) and all the blots were quantified using LANE 1D software version 1 (Sage Creation Science Co., Ltd., Beijing, China). The experiments were performed $\geq 3$ times.

Statistical analysis. Data are presented as the mean \pm standard deviation, and the differences between two groups were analyzed using Student's t-test. Statistical analyses were performed using SPSS 16.0 (SPSS, Inc., Chicago, IL, USA). 

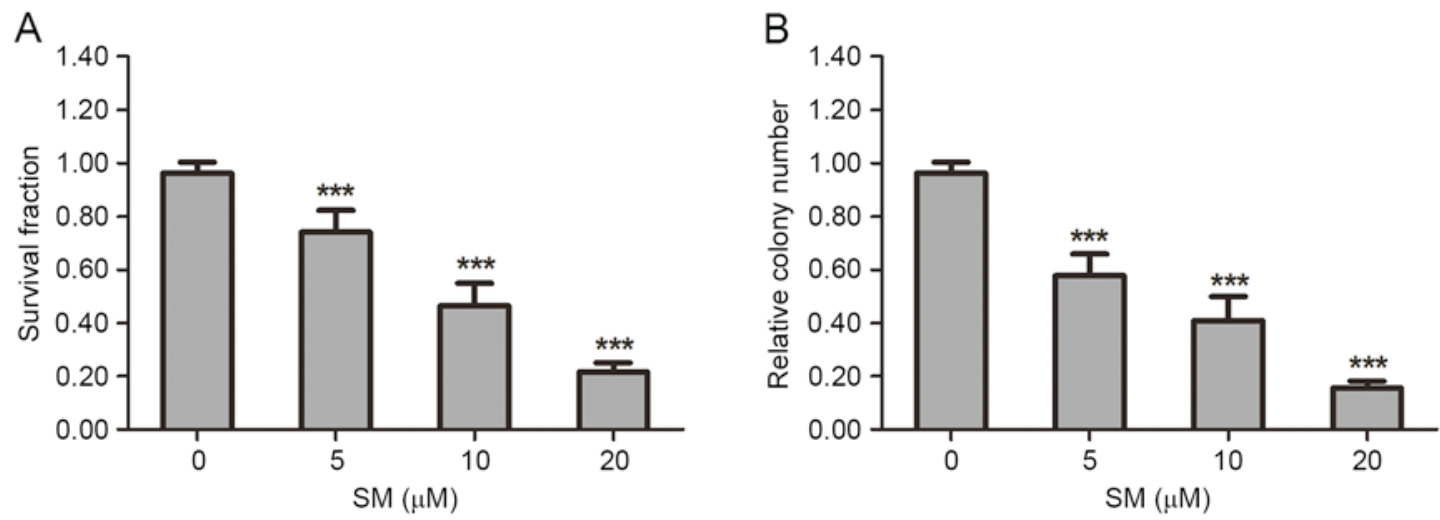

Figure 1. SM suppresses the proliferation viability of HepG2 cells. Cell viability and proliferation was examined by MTT and colony formation assays. (A) Following exposure to various concentrations $(0,5,10,20 \mu \mathrm{M})$ of SM for $24 \mathrm{~h}$, the HepG2 cells survival ratio was revealed to be dose-dependent. (B) HepG2 cells were treated with $0,5,10$ and $20 \mu \mathrm{M} \mathrm{SM}$ for 2 weeks, then stained and counted. The colony number was significantly reduced as the treatment concentration increased. Data are presented as the mean \pm standard deviation. ${ }^{* * *} \mathrm{P}<0.001$ vs. $0 \mu \mathrm{M}$ SM group. SM, solamargine.

$\mathrm{Oh}$

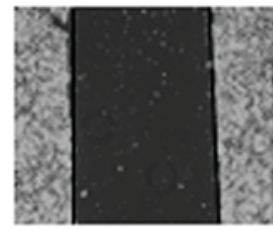

$12 \mathrm{~h}$

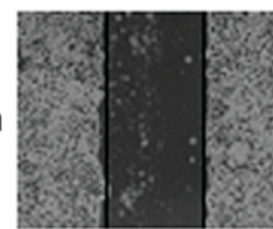

$24 \mathrm{~h}$

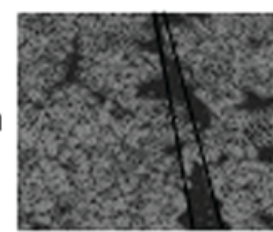

Control
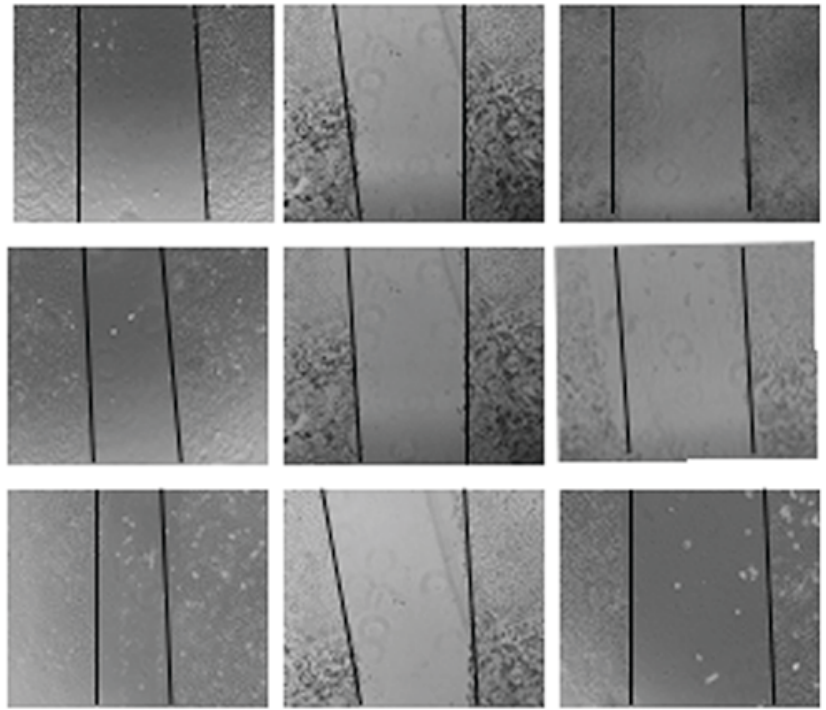

$5 \mu \mathrm{M}$

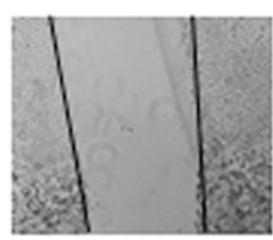

$10 \mu \mathrm{M}$

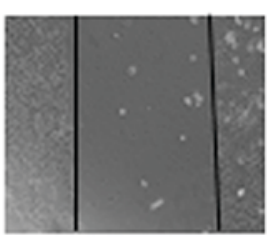

$20 \mu \mathrm{M}$

Figure 2. Migration ability as evaluated by wound-healing assays. HepG2 cells were treated with 5, 10 or $20 \mu$ M SM, and the width of the wound exhibited a lower propensity for closure compared with the control group. The untreated HepG2 cells filled the majority of the wounded area after $24 \mathrm{~h}$, whereas a distinct gap remained in the SM-treated groups. SM inhibited wound closure of the HepG2 cells in a dose-dependent manner. Magnification, $\mathrm{x} 40$. SM, solamargine.

$\mathrm{P}<0.05$ was considered to indicate a statistically significant difference. All the experiments were performed in at least in triplicate.

\section{Results}

Proliferation and viability of HepG2 cells is suppressed by $S M$. The suppressive effect of SM on HepG2 cell viability and proliferation was determined by MTT and colony formation assays. In the MTT analysis, HepG2 cells were treated with various concentrations $(0,5,10$ or $20 \mu \mathrm{M})$ of SM for $24 \mathrm{~h}$. The results revealed that the survival fraction of HepG2 cells was affected in a dose-dependent manner. At $20 \mu \mathrm{M}$ SM the survival rate $(21.7 \pm 3.5 \%)$ was the lowest (Fig. 1A). In the colony formation experiments, each well was seeded with 500 HepG 2 cells, then incubated for 2 weeks and stained, and the colony number was then counted. Following exposure to 5 , 10 or $20 \mu \mathrm{M} \mathrm{SM}$, the relative colony numbers were $57.7 \pm 4.3$,
$38.1 \pm 4.9$ and $15.7 \pm 2.5 \%$ compared with the control group $(\mathrm{P}<0.001)$. The colony number decreased in a dose-dependent manner (Fig. 1B).

Migration of HepG2 cells is attenuated by SM treatment. The migration was evaluated by wound-healing and Transwell assays. In the wound-healing assay, HepG2 cells were treated with $0,5,10$ or $20 \mu \mathrm{M}$ SM supplemented with $1 \%$ FBS. Following 12 and $24 \mathrm{~h}$, the width of the wound exhibited a lower propensity for closure compared with the that of the untreated cells. The untreated HepG2 cells filled the majority of the wounded area after $24 \mathrm{~h}$, whereas a distinct gap remained in the SM-treated groups after $24 \mathrm{~h}$, and the gaps were affected in a dose-dependent manner (Fig. 2). Furthermore, after $24 \mathrm{~h}$ and treatment with 10 and $20 \mu \mathrm{M} \mathrm{SM}$, respectively, the width of the gaps were increased compared with the gap at $12 \mathrm{~h}$ (Fig. 2). To confirm the inhibition effects, a Transwell assay was performed. HepG2 cells were 
A

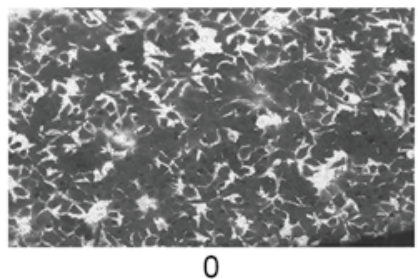

0

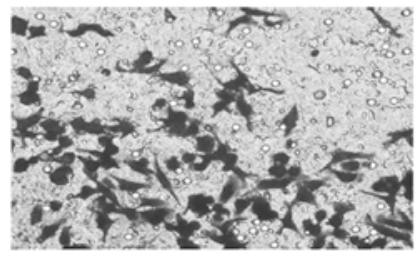

10
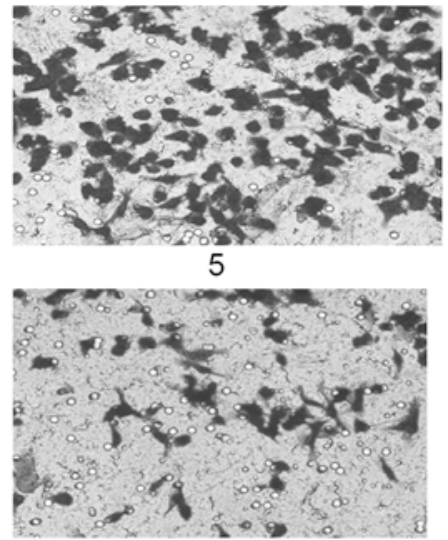

20
B

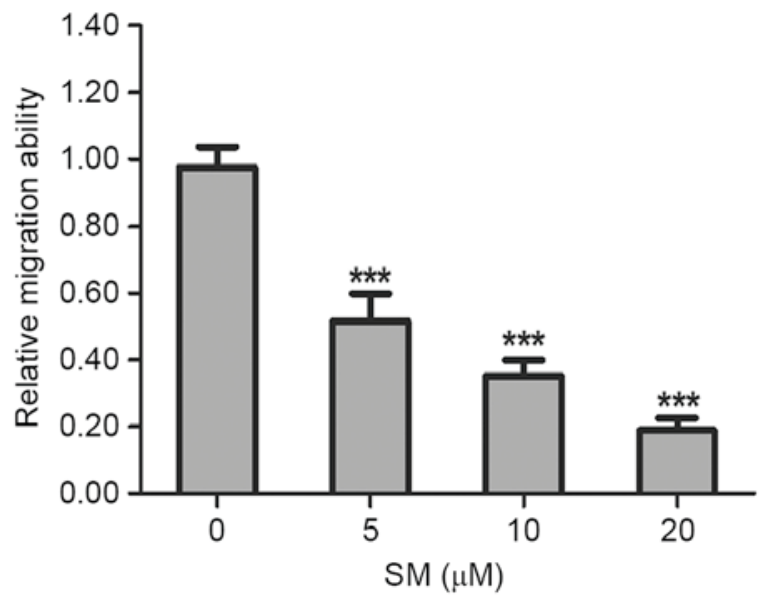

Figure 3. Migration ability of cells as evaluated by Transwell assay. (A) Following cell migration from the upper into the lower wells, the cells were stained, imaged and counted. Subsequent to treatment with 0, 5, 10 and $20 \mu \mathrm{M} \mathrm{SM}$, the migration number of HepG2 cells decreased as the concentration of SM increased. (B) Statistical results of relative migration ability. SM-treated cells revealed significant differences compared with the untreated cells. ${ }^{* * *} \mathrm{P}<0.001$ vs. $0 \mu \mathrm{M}$ SM treatment group. Magnification, x200. SM, solamargine.

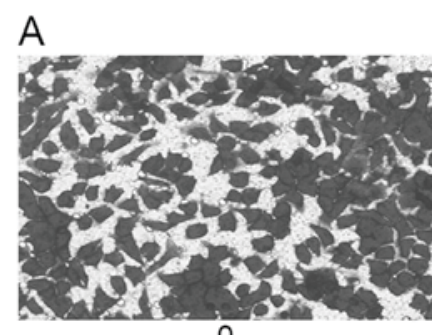

0

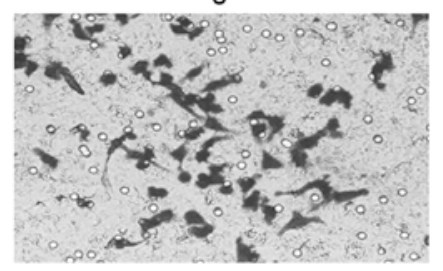

10

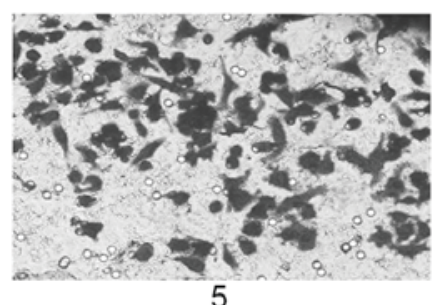

5

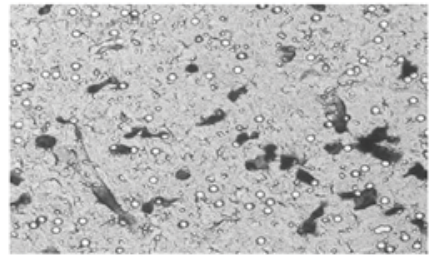

20
B

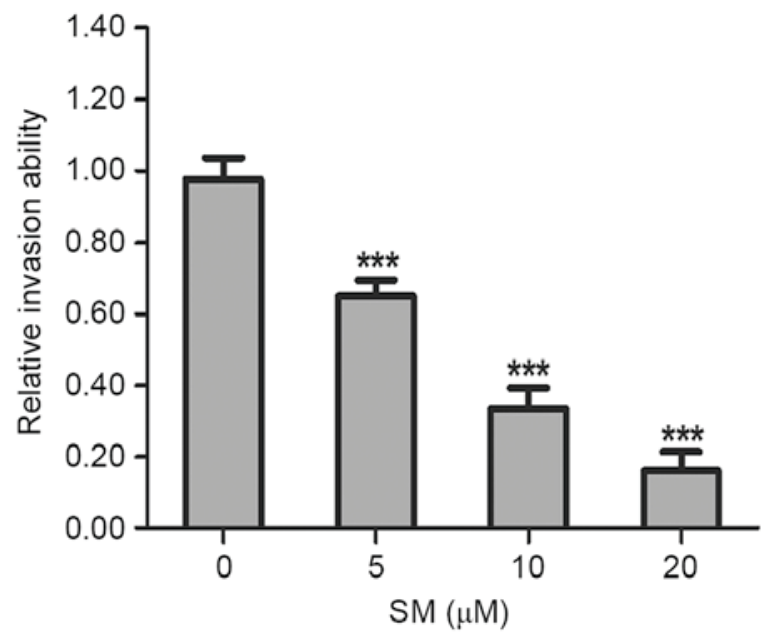

Figure 4. Invasive ability as detected by matrigel-coated Transwell assays. (A) Following exposure to SM, the number of HepG2 cells that penetrated from the upper chamber to the lower well decreased in a concentration-dependent manner. (B) Statistical results of relative invasion ability. The results are presented as the mean \pm standard deviation. ${ }^{* * *} \mathrm{P}<0.001$ vs. $0 \mu \mathrm{M}$ SM group. Magnification, $\mathrm{x} 200$. SM, solamargine.

treated with SM for $24 \mathrm{~h}$, then stained, imaged and evaluated. Compared with the untreated group, the mobility ratio of 5, 10 and $20 \mu \mathrm{M}$ SM-treated cells were 51.7 $\pm 8.1,35.3 \pm 4.5$ and $19.0 \pm 3.6 \%$, respectively (Fig. 3A). The relative migration ratios of the SM-treated HepG2 cells revealed significant differences compared with the untreated group $(\mathrm{P}<0.001$; Fig. 3B).

Invasion of HepG2 cells is suppressed by SM. Cell invasive capacity was evaluated by matrigel-coated Transwell assays. As presented in Fig. 4A, the invasive ability of the SM-treated cells decreased significantly as the SM concentration increased. Compared with the untreated cells, the relative invasion ratios of 5, 10 and $20 \mu \mathrm{M}$ SM-treated HepG2 cells were $65.0 \pm 4.6,33.7 \pm 5.5$ and $16.1 \pm 5.6 \%$, respectively. There were significant differences between the treated and untreated groups $(\mathrm{P}<0.001$; Fig. 4B). These results indicated that SM inhibited the invasive capacity of HepG2 cells.

Changes in expression level of EMT representative proteins in SM-treated cells. EMT is an important process in inducing cancer migration and invasion, which is often associated with a loss or decrease of E-ca, and an increase of Vimentin and $\mathrm{N}$-ca expression levels $(15,16)$. Thus, the present study examined whether EMT-associated protein expression levels changed in SM-treated cells. As presented in Fig. 5, the epithelial marker, E-ca, was upregulated compared with that in the control group, whereas the mesenchymal markers, Vimentin and N-ca were consistently downregulated in the SM-treated cells. Therefore, it was suggested that SM treatment decreased the migration and invasion abilities in hepatoblastoma cells by suppressing the process of EMT. 
A

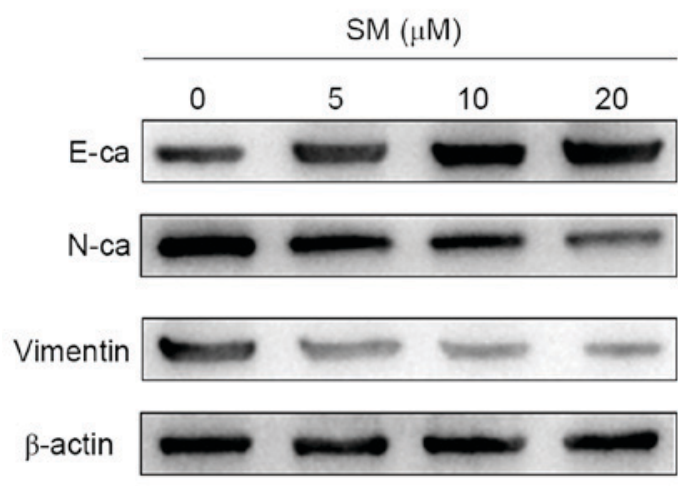

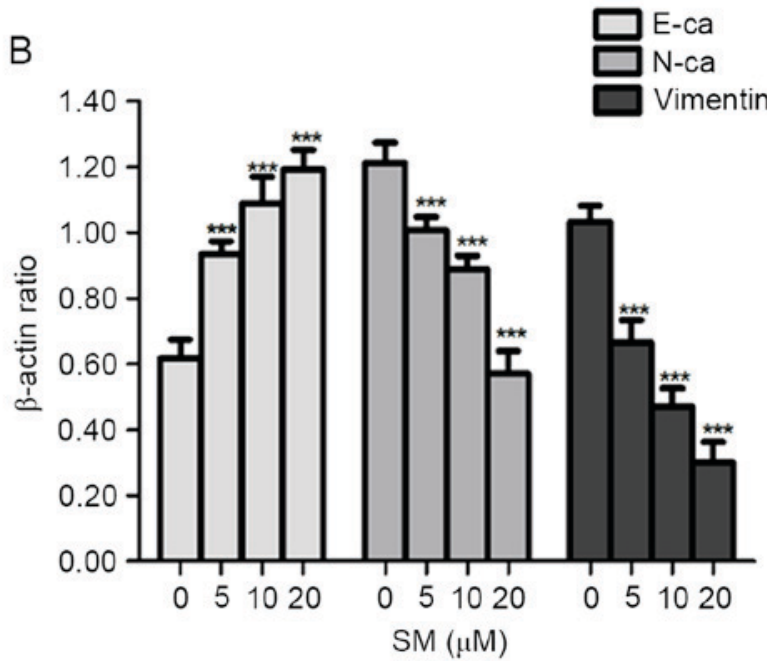

Figure 5. HepG2 cells were treated with various concentrations $(0,5,10,20 \mu \mathrm{M})$ of SM for $24 \mathrm{~h}$. (A) The expression levels of EMT representative proteins (E-ca, N-ca and Vimentin) in HepG2 cells were determined by western blotting analysis. $\beta$-actin was used as the loading control. (B) Statistical results of western blotting analysis. Results are representative of $\geq 3$ independent experiments. ${ }^{* * *} \mathrm{P}<0.001$ vs. $0 \mu \mathrm{M}$ SM group. SM, solamargine; E-ca, E-cadherin; N-ca, $\mathrm{N}$-cadherin.

\section{Discussion}

Previously, Chinese herbs have been demonstrated to contribute an effective function in the treatment of numerous diseases and have attracted worldwide attention $(23,24)$. Certain previous studies have reported that they Chinese herbs served important roles in regulating tumor cell behavior, including proliferation, apoptosis and metastasis (25-27). SM, extracted from Solanum incanum, is a traditional Chinese herb that was demonstrated to possess an effective function in inducing apoptosis of HepG2 and SMMC7721 cells in our previous study (21). In the present study, as conclusive results were not previously observed when investigating metastasis in SMMC7721 cells, the effects of SM on the migration and invasion on HepG2 cells were evaluated, and the concentration and treated durations were used as referenced in our previous study (21).

Previous studies have indicated that SM may suppress cell proliferation in numerous cancer cell lines (28-30). In the present study, the results of the MTT and colony formation assays further confirmed this hypothesis showing that SM effectively reduced cell proliferation in a concentration-dependent manner in HepG2 cells.

The results of wound-healing and Transwell experiments demonstrated that the migration ability of the HepG2 cells was decreased following treatment with various concentrations of SM. Furthermore, as the doses of SM increased, the suppression effect was enhanced. In the wound-healing assay, it was hypothesized that the width of the gap would decrease in a time-dependent manner, whereas after $24 \mathrm{~h}$ of treatment with 10 and $20 \mu \mathrm{M}$ concentrations of SM, the width of the gap was increased compared with the size of the gap following $12 \mathrm{~h}$. It was considered that this phenomenon was associated with the SM function in triggering HepG2 cells death by apoptosis (21). Use of a Matrigel-coated Transwell assay is a classical method to detect cell invasion, whereby the invasive HepG2 cells would digest the gel and penetrate the upper chamber to the lower wells. Following exposure to various concentrations of SM, the number of HepG2 cells in the lower chamber decreased greatly as the SM concentrations increased. The Matrigel-coated Transwell experiment indicated that SM inhibited the invasive viability of HepG2 cells efficiently.

Given the suppression effects of migration and invasion revealed in HepG2 cells, the present study subsequently investigated the underlying mechanism. EMT is a crucial event for metastasis in numerous types of cancer (10,31-33), and was first recognized as a feature of embryogenesis in the 1980s (34). During the transformation from the epithelial to the mesenchymal phenotype, epithelial cells lose their polygonal shape and acquire a spindle-shaped morphology, which provides the tumor cells enhanced motility and invasive abilities (35-37). At the molecular level, numerous previous studies have described the molecular pathways involved in EMT, and revealed that it is characterized an increase in $\mathrm{N}$-ca and Vimentin, but particularly by the downregulation of E-ca $(38,39)$. The western blot analysis of the present study demonstrated that the expression of E-ca was upregulated compared with the control group, whereas N-ca and Vimentin were consistently downregulated in SM-treated cells. Thus, it was suggested that SM inhibited the migration and invasion of HepG2 cells by blocking EMT.

The present study aimed to reveal the function and effects of SM in hepatoblastoma cells. However, as a traditional Chinese herb, SM has various functions and further studies are required to detect them. Taken together, the present findings suggested that SM may inhibit the migration and invasion viability of HepG2 cells by blocking EMT.

\section{Acknowledgements}

The present study was supported by the National Natural Science Foundation of China (grant no. 81502663), the Social Development Foundation of Jiangsu Province (grant no. BE2015668) and the Natural Science Foundation 
of Colleges and Universities in Jiangsu Province (grant no. 14KJD310001).

\section{References}

1. Linabery AM and Ross JA: Trends in childhood cancer incidence in the U.S. (1992-2004). Cancer 112: 416-432, 2008.

2. Fracp K J G A: Pathology of pediatric gastrointestinal and liver disease. Second edition. Anticancer Research 35: 234-234, 2015

3. Mclaughlin CC, Baptiste MS, Schymura MJ, Nasca PC and Zdeb MS: Maternal and infant birth characteristics and hepatoblastoma. Am J Epidemiol 163: 818-828, 2006.

4. Finegold MJ, Lopez-terrada DH, Bowen J, Washington MK and Qualman SJ; College of American Pathologists: Protocol for the examination of specimens from pediatric patients with hepatoblastoma. Arch Pathol Lab Med 131: 520-529, 2007.

5. Litten JB and Tomlinson GE: Liver tumors in children. Oncologist 13: 812-820, 2008.

6. Liu Z, Wang J, Mao Y, Zou B and Fan X: MicroRNA-101 suppresses migration and invasion via targeting vascular endothelial growth factor-C in hepatocellular carcinoma cells. Oncol Lett 11: 433-438, 2016.

7. Dai W, Wang F, He L, Lin C, Wu S, Chen P, Zhang Y, Shen M, Wu D, Wang C, et al: Genistein inhibits hepatocellular carcinoma cell migration by reversing the epithelial-mesenchymal transition: Partial mediation by the transcription factor NFAT1 Mol Carcinog 54: 301-311, 2015.

8. Bi Z, Liu W, Ding R, Wu Y, Dou R, Zhang W, Yuan X, Liu X, Xiong L, Guo Z and Mao C: A novel peptide, 9R-P201, strongly inhibits the viability, proliferation and migration of liver cancer HepG2 cells and induces apoptosis by down-regulation of FoxM1 expression. Eur J Pharmacol 796: 175-189, 2017.

9. Iwatsuki M, Mimori K, Yokobori T, Ishi H, Beppu T, Nakamori S, Baba $\mathrm{H}$ and Mori M: Epithelial-mesenchymal transition in cancer development and its clinical significance. Cancer Sci 101: 293-299, 2010.

10. Thiery JP, Acloque H, Huang RY and Nieto MA: Epithelial-mesenchymal transitions in development and disease. Cell 139: 871-890, 2009.

11. Nagathihalli NS and Merchant NB: Src-mediated regulation of E-cadherin and EMT in pancreatic cancer. Front Biosci (Landmark Ed) 17: 2059-2069, 2012.

12. Bates RC and Mercurio AM: The epithelial-mesenchymal tansition (EMT) and colorectal cancer progression. Cancer Biol Ther 4: 365-370, 2005.

13. Zhu C, Li J, Cheng G, Zhou H, Tao L, Cai H, Li P, Cao Q, Ju X, Meng X, et al: MiR-154 inhibits EMT by targeting HMGA2 in prostate cancer cells. Mol Cell Biochem 379: 69-75, 2013.

14. Creighton CJ, Chang JC and Rosen JM: Epithelial-mesenchymal transition (EMT) in tumor-initiating cells and its clinical implications in breast cancer. J Mammary Gland Biol Neoplasia 15: 253-260, 2010.

15. Thiery JP: Epithelial-mesenchymal transitions in tumour progression. Nat Rev Cancer 2: 442-454, 2002.

16. Grünert $S$, Jechlinger $M$ and Beug $H$ : Diverse cellular and molecular mechanisms contribute to epithelial plasticity and metastasis. Nat Rev Mol Cell Biol 4: 657-665, 2003.

17. Yang J, Mani SA, Donaher JL, Ramaswamy S, Itzykson RA, Come C, Savagner P, Gitelman I, Richardson A and Weinberg RA: Twist, a master regulator of morphogenesis, plays an essential role in tumor metastasis. Cell 117: 927-939, 2004.

18. Cowin P, Rowlands TM and Hatsell SJ: Cadherins and catenins in breast cancer. Curr Opin Cell Biol 17: 499-508, 2005.
19. Junghans D, Haas IG and Kemler R: Mammalian cadherins and protocadherins: About cell death, synapses and processing. Curr Opin Cell Biol 17: 446-452, 2005

20. Lorey S, Porzel A and Ripperger H: Steroid alkaloid glycosides from Solanum coccineum. Phytochemistry 41: 1633-1635, 1996.

21. Xie X, Zhu H, Yang H, Huang W, Wu Y, Wang Y, Luo Y, Wang D and Shao G: Solamargine triggers hepatoma cell death through apoptosis. Oncol Lett 10: 168-174, 2015.

22. Albini A, Iwamoto Y, Kleinman HK, Martin GR, Aaronson SA, Kozlowski JM and McEwan RN: A rapid in vitro assay for quantitating the invasive potential of tumor cells. Cancer Res 47: 3239-3245, 1987.

23. Chen W, Lim CE, Kang HJ and Liu J: Chinese herbal medicines for the treatment of type A H1N1 influenza: A systematic review of randomized controlled trials. PLoS One 6: e28093, 2011.

24. Lam W, Bussom S, Guan F, Jiang Z, Zhang W, Gullen EA, Liu SH and Cheng YC: The four-herb Chinese medicine PHY906 reduces chemotherapy-induced gastrointestinal toxicity. Sci Transl Med 2: 45ra59, 2010

25. Liu J, Shu Y, Zhang Q, Liu B, Xia J, Qiu M, Miao H, Li M and Zhu R: Dihydromyricetin induces apoptosis and inhibits proliferation in hepatocellular carcinoma cells. Oncol Lett 8: 1645-1651, 2014

26. Jiang J and $\mathrm{Hu} \mathrm{C}$ : Evodiamine: A novel anti-cancer alkaloid from Evodia rutaecarpa. Molecules 14: 1852-1859, 2009.

27. Jang SY, Lee JK, Jang EH, Jeong SY and Kim JH: Shikonin blocks migration and invasion of human breast cancer cells through inhibition of matrix metalloproteinase-9 activation. Oncol Rep 31: 2827-2833, 2014.

28. Sun L, Zhao Y, Li X, Yuan H, Cheng A and Lou H: A lysosomal-mitochondrial death pathway is induced by solamargine in human K562 leukemia cells. Toxicol In Vitro 24: 1504-1511, 2010.

29. Li X, Zhao Y, Wu WK, Liu S, Cui M and Lou H: Solamargine induces apoptosis associated with p53 transcription-dependent and transcription-independent pathways in human osteo-sarcoma U2OS cells. Life Sci 88: 314-321, 2011.

30. Ding X, Zhu FS, Li M and Gao SG: Induction of apoptosis in human hepatoma SMMC-7721 cells by solamargine from Solanum nigrum L. J Ethnopharmacol 139: 599-604, 2012.

31. Thompson EW, Newgreen DF and Tarin D: Carcinoma invasion and metastasis: A role for epithelial-mesenchymal transition? Cancer Res 65: 5991-5995, 2005.

32. Kalluri R and Weinberg RA: The basics of epithelial-mesenchymal transition. J Clin Invest 119: 1420-1428, 2009.

33. Cardiff RD: Epithelial to mesenchymal transition tumors: Fallacious or Snail's pace? Clin Cancer Res 11: 8534-8537, 2005.

34. Thiery JP: Epithelial-mesenchymal transitions in development and pathologies. Curr Opin Cell Biol 15: 740-746, 2003.

35. Thiery JP and Sleeman JP: Complex networks orchestrate epithelial-mesenchymal transitions. Nat Rev Mol Cell Biol 7: 131-142, 2006.

36. Klymkowsky MW and Savagner P: Epithelial-mesenchymal transition: A cancer researcher's conceptual friend and foe. Am J Pathol 174: 1588-1593, 2009.

37. Christiansen JJ and Rajasekaran AK: Reassessing epithelial to mesenchymal transition as a prerequisite for carcinoma invasion and metastasis. Cancer Res 66: 8319-8326, 2006.

38. De Craene B and Berx G: Regulatory networks defining EMT during cancer initiation and progression. Nat Rev Cancer 13: 97-110, 2013.

39. Lamouille S, Xu J and Derynck R: Molecular mechanisms of epithelial-mesenchymal transition. Nat Rev Mol Cell Biol 15: 178-196, 2014. 